\section{P33 'LIGHT TOUCH' TELEMONITORING FOR PEOPLE WITH COPD IN LOTHIAN: A PILOT EVALUATION WITH NESTED QUALITATIVE STUDY}

${ }^{1} \mathrm{HJ}$ Pinnock, ${ }^{1} \mathrm{M}$ MacNab, 'S Lee, ${ }^{1} \mathrm{~L}$ McCloughan, ${ }^{2} \mathrm{~J}$ Hanley, ${ }^{3} \mathrm{~A}$ Lindsay, ${ }^{1} \mathrm{~B}$ McKinstry. ${ }^{1}$ The University of Edinburgh, Edinburgh, UK; ${ }^{2}$ Edinburgh Napier University, Edinburgh, UK; ${ }^{3}$ NHS Lothian, Edinburgh, UK

\subsection{6/thoraxjnl-2014-206260.183}

Background and aim Professionally monitored telehealthcare has significant workload implications, but qualitative work suggested that pulse oximetry could potentially contribute to selfmonitoring. We aimed to evaluate the acceptability and perceived utility of a COPD 'Light Touch' service.

'Light Touch' intervention People with COPD used a pulse oximeter and symptom diary to self-monitor and self-refer according to a self-management plan. The service was overseen (though not actively monitored) by community-based respiratory/long-term conditions teams who were contactable by a telephone helpline.

Method We undertook a before-and-after study with quantitative data collection at baseline and six-months. Outcomes were St George's Respiratory Questionnaire (SGRQ), Hospital Anxiety and Depression Scale (HADS) and service use. Nested semistructured interviews with patients (at baseline and six-months) and managers, and a focus group of healthcare professionals explored perceptions of the service.

Results We recruited 51 patients. Quality-of-Life (SGRQ): 21 (46\%) participants improved by $\geq 4$ (the minimum important difference); 12 (26\%) deteriorated by $\geq 4$. HADS improved: more participants had normal scores for anxiety $(65 \%)$ and depression $(80 \%)$ at 6 months than at baseline (51\% and 64\%). There were fewer surgery consultations and more telephone consultations, antibiotic, oral steroid and nebulised therapy prescriptions recorded during the study period compared to the previous year. Only 18 (39\%) contacted the Light-Touch Helpline.

We conducted interviews with 20 participants (36 interviews), 6 managers, and a focus group of 8 clinicians. Patients were generally positive and embraced 'Light-Touch' telemonitoring as part of their daily self-surveillance. The readings were reassuring and gave them confidence to make self-management decisions. Most patients did daily checks though several had stopped routine monitoring preferring to 'check their readings as and when the need arises'. Healthcare professionals were concerned that patients had disengaged with their service. Few patients contacted the clinical teams for help or advice during the study and 6-monthly telephone reviews were introduced to maintain contact.

Conclusion 'In contrast to professionally-monitored telehealthcare, 'Light-Touch' seemed to reduce the contacts between patients and professionals. Whilst this may represent effective self-management, there were concerns that loss of engagement with healthcare services may be detrimental to achieving prompt management of exacerbations.

\section{P34 WHAT IS INTEGRATED CARE AND WHAT IS THE VALUE OF AN INTEGRATED RESPIRATORY SPECIALIST?}

${ }^{1} \mathrm{NJ}$ Roberts, ${ }^{2} \mathrm{M}$ Ward, ${ }^{3} \mathrm{IS}$ Patel, ${ }^{4} \mathrm{~J}$ Yorke, ${ }^{5} \mathrm{~J}$ Williams, ${ }^{6} \mathrm{R}$ Walters, ${ }^{7} \mathrm{M}$ McKevitt, ${ }^{8} \mathrm{~S}$ Edwards. ${ }^{1}$ Glasgow Caledonian University, Glasgow, UK; ${ }^{2}$ Sherwood Forest Hospitals, Sutton in Ashfield, UK; ${ }^{3}$ Kings College Hospital London, London, UK; ${ }^{4}$ University of Manchester, Manchester, UK; ${ }^{5}$ Halton General Hospital, Runcorn, UK; ${ }^{6}$ Mansfield Community Hospital, Mansfield, UK; ${ }^{7}$ British Lung Foundation, London, UK; ${ }^{8}$ British Thoracic Society, London, UK

10.1136/thoraxjn-2014-206260.184
Aim The way we deliver healthcare in the UK is changing, joining up care between the different health sectors has created a new field of "integrated care". Recent publications from the Kings Fund, Nuffield Trust and National Voices has shown that it is difficult to define "integrated care". This project surveyed health professionals on their views about integrated care and the value of integrated respiratory specialists.

Method A questionnaire was sent to all BTS members in Oct 2013 on the role of integrated care specialists, 216 responses were received.

Results Most respondents (82.5\%, 178/216) included integration of primary and secondary care in their definition of integrated care, only $36.5 \%(65 / 178)$ included community, and a smaller number included social care as part of the definition. In the free-text there was also emphasis on the bridging role of the post, and providing "seamless care" across sectors.

$62 \%(86 / 139)$ agreed that integrated respiratory specialists had added value (compared to respiratory specialist roles); providing continuity of care for a defined population (87\%, [121/139), and $77 \%(106 / 138)$ agreed that they improve outcomes for patients with a long term condition. Eighty-nine percent (124/140) also agreed that integrated specialists improve relationships between primary and secondary care. When asked the most important role that an integrated respiratory specialist should undertake $(98$ comments), the provision of specialist leadership, clinical decisionmaking and supervision (20 comments) were highly rated. Teaching (10 comments) and providing liaison support for the whole pathway were also important ( 9 comments).

Conclusion $82 \%$ of respondents (178/216) included integration of primary and secondary care in their definition of integrated care. However $14.4 \%$ were unsure of what integrated care was. Considerable more work is needed to promote this new way of working and potential career pathway. However of those who did know about these roles, a large majority agreed that these roles had added value compared to traditional specialist roles.

Funded by the BTS.

Abstracts M35 to M43 can be found on pages A208-A211.

\section{Asthma: investigation and organisation of care}

\section{\begin{tabular}{|l|l}
\hline P44 ASSESSMENT OF SPIROMETRY AND IMPULSE \\
\hline
\end{tabular} OSCILLOMETRY IN RELATION TO ASTHMA CONTROL}

A Manoharan, WJ Anderson, J Lipworth, BJ Lipworth. University of Dundee, Dundee, UK

10.1136/thoraxjnl-2014-206260.185

Background Guidelines advocate the use of spirometry to assess pulmonary function in asthmatic patients. Commonly used measures include forced expiratory volume in 1 second $\left(\mathrm{FEV}_{1}\right)$, forced expiratory ratio $\left(\mathrm{FEV}_{1} / \mathrm{FVC}\right)$ and forced mid-expiratory flow between $25 \%$ and $75 \%$ of forced vital capacity $\left(\mathrm{FEF}_{25-75}\right)$. Impulse oscillometry (IOS) is an effort independent test performed during tidal breathing. IOS may be used to assess the total and central airway resistance at $5 \mathrm{~Hz}$ (R5) and $20 \mathrm{~Hz}$ (R20) respectively and hence derive the peripheral airway resistance from the difference (R5-R20).

Objective To compare spirometry and IOS as tests of global airway function (i.e. $\mathrm{FEV}_{1}, \mathrm{FEV}_{1} / \mathrm{FVC}, \mathrm{R} 5$ ) and putative measures of small airways function (i.e. $\mathrm{FEF}_{25-75}, \mathrm{R} 5-\mathrm{R} 20$ ) and their relationship to long-term asthma control. 